\title{
Research on the Acquiring Users' Needs and Providing Precision Information Service by Sci-tech Novelty Search Training Course
}

\author{
Junbo Zhu \\ Xiamen University Library, Xiamen 361005, China. \\ 40712853@qq.com
}

\begin{abstract}
Understanding and acquiring the needs of readers is the prerequisite for developing user-driven information consulting services. In the field of library, the traditional ways of obtaining users' needs mainly include reader consultation, library guidance, special training, librarian investigation and so on. With the improvement of library information consultation services, the traditional ways of obtaining users' needs are increasingly difficult to meet the actual needs. How to accurately grasp the actual needs of users and meet the personalized needs of users is an urgent problem to be solved. Combining with the actual work, this study plans to starting from the research topic selection of graduate students, through the training of graduate students in sci-tech novelty search literacy, we can analyze their needs, obtain specific information needs and service needs, and then rely on the resources and services of the library to meet their needs. Personalized needs, so as to explore a new user-driven information consulting service model.
\end{abstract}

Keywords: Sci-tech Novelty Search; Acquiring Users' Needs; Precision Information Service.

\section{Introduction}

It is an important historical stage of Library development in 2016-2020, which is called the 13th Five-Year Plan period of China. Faced with the unique opportunities, risks and challenges, "transformation and development" is the main feature of the global library cause in this period [1]. On December 31, 2015, the Ministry of Education promulgated the Regulations for Libraries of Universities and Colleges, emphasizing that the construction and development of libraries should be compatible with the construction and development of schools, whose level is an important symbol of the overall level of schools [2]. In 2015, the State Council promulgated the Overall Plan for Promoting the Construction of World-class Universities and First-class Disciplines, aiming at promoting a number of high-level universities and disciplines to enter the world-class ranks or forefront [3]. On September 21, 2017, with the publication of the list of world-class universities and first-class disciplines, a number of universities entered the implementation stage of "double first-class" construction. Driven by the "double first-class" construction project, on the one hand, university libraries need to be more clear about their own positioning and functions, focusing on the role of personnel training, scientific research, social services and cultural heritage and innovation; on the other hand, the value of "people-oriented" gradually penetrates into the hearts of the people, with the development of information technology. The trend of diversification of user needs is becoming more and more obvious. University libraries should be clearer about the needs of core service objects and implement the concept and principle of "user-driven" service.

At present, the user-driven service of University Libraries mainly takes various forms of subject service, which first appeared in American Research University Libraries in the mid and late 1970s. In 1998, Tsinghua University took the lead in implementing the subject librarian system in China. Subsequently, Wuhan University, Xi'an Jiaotong University, Peking University and Fudan University have implemented the subject librarian system one after another. Since then, more and more university libraries have tried to some extent [4,5]. However, in practice, except for a few successful exceptions, there are still many colleges and universities whose actual effect of subject service is not ideal, which is far from the original intention of setting up the system. The service of subject librarians is out of touch with the needs of users, and the lack of user acceptance is a prominent problem in the course of subject service. The main manifestations are as follows: (1), the individualization, 
specialization and depth of subject service are not enough, and the existing subject service lacks good user experience, which leads to the low recognition of users to subject librarians. (2) Over-seeking to provide cutting-edge services for teachers and management, neglecting basic services, especially undergraduate groups are often placed outside subject services, while the demand for subject information of postgraduates has not been well valued and met [4]. (3) The innovation service is insufficient, and the traditional form of information service is still the main form. Most of them are in the exploratory stage of embedding teaching and integrating scientific research. There is still a gap between them [6-9]. All these seriously affect and restrict the further development of subject services, and affect the effective use of document resources by users in teaching, scientific research and learning.

\section{Research Status of Library Users' Needs Acquisition}

With the rapid development of modern science and technology, the functions, services and technological means of libraries are constantly bringing forth new ideas, but "all for readers" is still the unchanged purpose of libraries. However, facing the massive emergence of various kinds of information and the endless emergence of information acquisition means, how should university libraries provide services for users? For University libraries, in addition to introducing new technologies and methods, they should base themselves on the needs of their users, formulate appropriate strategies and provide effective services.

As far as the field of library is concerned, the traditional ways of obtaining users' needs mainly include reader consultation, library guidance, special training, sample survey and librarian survey $[10,11]$. In practical work, these methods have their own advantages and disadvantages, including:

(1) user demand consultation, including reader consultation, library guidance and so on. User demand consultation is currently the most common way of using the library to solicit opinions and needs from users. Specifically, it includes many forms, such as the permanent entity consultation post in the library lobby, the online or email consultation on the library website, the librarian's mailbox or reader's opinion column, and the interactive column of the business department, etc. The greatest advantage of these approaches is direct and convenient, but the shortcomings are obvious. Because this form requires users to express their needs to the library on their own initiative, most users may not be willing to spend time commenting, or even if they are willing to express their needs clearly. This leads to the instability of the sources of demand information directly expressed by the users that the library can collect, and the number is very limited.

(2) Sampling survey is an active inquiry and exchange of users' intentions. Investigators will need to obtain facts, decompose them into smaller variables and indicators, extract specific sample populations, and collect relevant data through questionnaires or interviews [12]. For example, Peking University Library conducted a survey of readers' needs in 2012 through questionnaires, and found that different groups of readers in universities have different attitudes towards libraries [13]. The advantage of user sampling survey is that it can control the whole process, and the information obtained is relatively comprehensive and objective, but there are also many problems: first, it has subjective orientation. When designing the questionnaire in advance, it is inevitable to incorporate the subjective will of researchers. The second is the lack of individuality. Because the sample survey pays attention to the needs of the whole group, most of the surveys are universal problems, and it is difficult to deal with the special needs of individuals. Third, the cost is high. Sampling Survey needs a large amount of manpower and financial resources, and the cycle is also longer.

(3) Embedded service means that library service personnel enter user groups through virtual and physical ways, formulate strategies from the user's point of view, and provide personalized services. Embedded services are very popular in libraries because they make up for the shortcomings of sample surveys which are broad and individualized. At present, the main methods we adopt are: establishing long-term cooperative relations with colleges, academic teams or individuals; entering the classroom to understand students' needs; entering the research group to participate in the scientific research process; establishing an interactive platform to communicate with users, and so on. The libraries of 
Tsinghua University, Shanghai Jiaotong University and Xiamen University have accumulated a lot of theoretical and practical experience in embedded subject services. Compared with the sample survey partial reorganization, the greatest advantage of embedded services is that it can fine-tune the needs of users, but there are also many drawbacks in embedded services. First, the investment cost is high and the income is small. In order to have an in-depth dialogue with users in an academic field, subject librarians often need to spend a lot of time and energy to familiarize themselves with related subjects. Nevertheless, it is still difficult to ensure that users in this field are satisfied. Second, the service area is narrow. Academic development has led to more and more refinement of disciplines, and library service personnel can only select a relatively small part of the numerous research fields to track in depth [15].

The traditional way has its irreplaceable function, but with the improvement of library information consultation service, the traditional access to user needs is increasingly difficult to meet the actual needs. Failure to understand users' needs in time will inevitably affect the rational allocation of library resources and users' trust in the library. In order to better serve users, university libraries need to expand their thinking, integrate traditional and modern technologies, and seek more effective ways and methods in obtaining users' needs.

\section{Acquiring Users' Needs and Providing Precision Information Service by Sci- Tech Novelty Search Training Course.}

The subject service of Xiamen University Library has been implemented for 17 years since 2001, and a series of practice has been carried out. The "part-time and decentralized" subject librarian model is implemented in the library, that is, subject librarians' subject services are all part-time, and they also need to carry out other services in their libraries. Secondly, for subject librarians with different subject backgrounds, subject services basically adopt one-to-one mode, that is, a subject librarian serves a related professional department. Therefore, besides the routine subject services such as online consultation, freshman training and so on, the subject services of the relevant subject librarians can also bring their personal expertise into full play to carry out the new subject services work [16].

Under the policy of library leaders encouraging librarians to innovate, science and technology novelty retrieval librarians carry out subject service innovation according to their work characteristics, work nature and work time allocation, and carry out user demand acquisition and precise chemical subject service based on science and technology novelty retrieval training courses. Specifically, a practical course of scientific and technological novelty search is carried out for graduate freshmen; furthermore, guided by the novelty search of graduate students, with the completion of novelty search reports as the task goal, through personalized guidance, students' needs for novelty search are grasped and served accurately. Its characteristics include: (1) Targets: For newly enrolled first-year graduate students, recruit groups who are interested in scientific and technological novelty search and have learning motivation. (2) Teaching mode: task-based PBL (problem-centered) +TBL (emphasis on teamwork) +SPOC (small-scale restrictive) hybrid teaching mode. (3) Ways of realization: students self-study online and search literature; postgraduate tutors cooperate with science and technology novelty searchers to carry out off-line discussions, guidance, collaboration and sharing. With the completion of novelty search report as the task goal, according to the process design: stage tasks, learning links, evaluation nodes. The whole process of novelty search operation practice, teachers according to each student's different problems for personalized guidance. Cooperative learning is accomplished through group discussion. Main nodes: key points of science and technology, novelty search points, retrieval strategies, retrieval results analysis, and novelty search conclusions. (4) Practical results have achieved such effects as topic selection guidance, information support, academic literacy, collaborative innovation and role integration. Topic selection guidance: It can judge the novelty of topic selection comprehensively, systematically and objectively, avoid duplication and improve the quality of scientific research. Intelligence support: It can grasp the frontier information of disciplines in real time, and provide information support for tutors' research and disciplines team. Academic literacy: To cultivate the comprehensive ability of capturing, 
processing and researching information, improve academic information literacy, and benefit for life. Collaborative innovation: Through self-study and group discussion, relevant research groups will be formed, which will contribute to academic exchanges and collaborative innovation. Role integration: Enter the practical link of scientific research topic selection ahead of time, and win more time for the research of postgraduate stage.

\section{Experience Summary of the Above Subject Service Model}

Through the above-mentioned novelty searchers as the core, and driven by the needs of novelty analysis of postgraduate opening reports, we have carried out targeted practice of subject service. The practice is reader-centered, focusing on tapping potential needs and actively expanding resources outside the library to serve readers; novelty searchers of science and technology play a more important role in teaching and learning, not only as a passive service provider, but also actively participate in the learning of readers through a series of specific service projects. Study and research task process. On this basis, in order to improve the effectiveness of subject services, libraries should provide omnipresent resources support, including paper resources, digital resources, audio-visual resources, social resources, print and copy, software systems, practical tools and other resources; and provide professional personnel support, such as librarians, technicians, teachers, student assistants. We should strengthen cooperation with other institutions, cooperate with scientific research departments, teaching departments, off-campus experts and social institutions, and enrich library services.

\section{Summary}

Through the above-mentioned novelty searchers as the core, and driven by the needs of novelty analysis of postgraduate opening reports, we have carried out targeted practice of subject service. The practice is reader-centered, focusing on tapping potential needs and actively expanding resources outside the library to serve readers; novelty searchers of science and technology play a more important role in teaching and learning, not only as a passive service provider, but also actively participate in the learning of readers through a series of specific service projects. Study and research task process. On this basis, in order to improve the effectiveness of subject services, libraries should provide omnipresent resources support, including paper resources, digital resources, audio-visual resources, social resources, print and copy, software systems, practical tools and other resources; and provide professional personnel support, such as librarians, technicians, teachers, student assistants. We should strengthen cooperation with other institutions, cooperate with scientific research departments, teaching departments, off-campus experts and social institutions, and enrich library services.

\section{Acknowledgements}

This research was financially supported by the Fujian Young and Middle-aged Teachers' Educational Research Project in 2017 (Grant NO. JZ170299).

\section{References}

[1]. Chen Chuanfu, Feng Changyang, Chen Yi. Exploring the Normalized Transformation Development Model of Libraries Facing a Well-off Society in an All-round Way [J]. Journal of Chinese Library, 2016 (1): 4-20.

[2]. Ministry of Education. Regulations for Library of Universities and Colleges [EB/OL]. [2019-94]. http://www.moe.edu.cn/srcsite/A08/moe_736/s3886/201601/t2019120_228487.html.

[3]. The State Council. Notice of the State Council on Issuing and Promoting the Overall Plan for the Construction of World-class Universities and First-class Disciplines [EB/OL]. [2019-9-4]. http://www.gov.cn/zhengce/content/2015-11/05/content_10269.htm. 
[4]. Wan Wenjuan. Practice and Deficiency Analysis of Subject Service in University Library of "985 Project" [J] Library Science Research, 2012 (3): 82-87.

[5]. Lu Li. Investigation and Analysis on the Current Situation of Subject Service in University Library of "211 Project" [J]. Library Science Research, 2013 (4): 59-63.

[6]. Zhao Min, Yu Jing. Research on Micro-innovation of Subject Service Design and Practice Development Course of Subject Service in the Library of Beijing Normal University [J]. Information Journal, 2015 (1): 200-202.

[7]. Zeng Xiaomu, Lin Jia. Subject Service Practice Based on Subject Effective Information Behavior: Taking Mathematics Discipline of Tsinghua University as an Example [J]. Journal of Academic Library, 2014 (3): 85-90.

[8]. Song Haiyan, et al. Practical exploration of embedded subject services for scientific research teams [J]. Library and information work, 2012 (1): 27-30.

[9]. Liu Suqing, et al. Multidimensional Expansion and Deepening of Subject Services - Focus and Reflection on Subject Services of Peking University Library [J]. Journal of Academic Library, 2012 (5): 18-22.

[10]. Gui Luomin. Research on user demand acquisition mode of University Library Based on big data thinking [J]. Journal of Jiaozuo Normal University, 2014, 30 (03): 84-88.

[11]. Zhang Yu. Approaches to Information Acquisition for Library Users' Needs [J]. Jiangxi Journal of Library Science, 2012, 42 (01): 122-124.

[12]. Yuan Fang. Course on Social Research Methodology [M]. Beijing: Peking University Press, 1997:128-131.

[13]. Zhao Fei. A Study on the Difference of Reader Group Demand in Colleges and Universities: Taking the 2010 Reader Demand Survey of Peking University Library as an example [J]. Journal of Academic Library, 2012 (4): 76-82.

[14]. Huang Qinling. Practice and characteristics of embedded subject service innovation for internationalized faculties --- Taking mechanical dynamics service of Shanghai Jiaotong University Library as an example [J]. Library and Information Work, 2012 (11): 69-71.

[15]. Ai Chunyan, et al. Discussion on the New Mode of Subject Service of University Library with Reader Participation [J]. Journal of Academic Library, 2011 (5): 70-72.

[16]. Liu Wenying, Lin Jing, Li Zheng. Practice of subject service reform in Xiamen University Library [J]. Agricultural Network Information, 2018 (03): 64-67. 